John Carroll University

Carroll Collected

$12-2017$

\title{
Avoiding Cognitive Biases in Clinical Decision Making: Commentary on "EvidenceBased Assessment as an Integrative Model for Applying Psychological Science to Guide the Voyage of Treatment"
}

Anthony M. Tarescavage

John Carroll University, atarescavage@jcu.edu

Yossef S. Ben-Porath

Kent State University

Follow this and additional works at: https://collected.jcu.edu/fac_bib_2017

Part of the Psychology Commons

\section{Recommended Citation}

Tarescavage, Anthony M. and Ben-Porath, Yossef S., "Avoiding Cognitive Biases in Clinical Decision Making: Commentary on "EvidenceBased Assessment as an Integrative Model for Applying Psychological Science to Guide the Voyage of Treatment”" (2017). 2017 Faculty Bibliography. 97.

https://collected.jcu.edu/fac_bib_2017/97

This Article is brought to you for free and open access by the Faculty Bibliographies Community Homepage at Carroll Collected. It has been accepted for inclusion in 2017 Faculty Bibliography by an authorized administrator of Carroll Collected. For more information, please contact connell@jcu.edu. 
Avoiding Cognitive Biases in Clinical Decision Making: Commentary on "EvidenceBased Assessment as an Integrative Model for Applying Psychological Science to Guide the Voyage of Treatment"

Anthony M. Tarescavage (D), John Carroll University Yossef S. Ben-Porath, Kent State University

Key words: applied assessment, assessment, cognitive bias, evidence-based assessment. [Clin Psychol Sci Prac, 2017]

Y oungstrom et al. (2017) have proposed and described in great depth an ambitious model of evidence-based assessment designed to evolve the current standards of mental health care. They integrate a number of clinical assessment principles into their model, such as a careful review of psychometrics as well as use of measures to diagnose psychopathology, plan treatment, and measure patient outcomes. These, of course, are not new ideas. In fact, they are well-established and well-validated principles. As the authors point out, however, sound assessment principles are not being routinely applied by practitioners in a comprehensive and systematic way, thereby limiting their positive impact on patient care. Why is this the case? We were persuaded by the authors that a primary factor is that practitioners are not trained in an integrated model for evaluating and comprehensively using psychological assessments. That is, even if practitioners are knowledgeable of sound assessment principles, there is little guidance on how to comprehensively apply these practices to their settings for maximum benefit.

Address correspondence to Anthony $M$. Tarescavage, Department of Psychological Science, John Carroll University, 1 John Carroll Boulevard, University Heights, OH 44118. Email: atarescavage@jcu.edu.
Youngstrom and colleagues' model of evidence-based assessment provides this guidance.

Youngstrom and colleagues (2017) introduce their model of evidence-based assessment by way of an analogy-that a client's progress through treatment is akin in some ways to a space voyage. They use this analogy to illustrate how preparation for treatment, by way of current psychological assessment practices, is much less efficient and effective than what would be expected for space travel. The analogy is used to highlight the need for comprehensive, applied models of psychological assessment, such as evidence-based assessment.

We propose that psychological treatment is also like a winter sea voyage. The clinician is the captain, and his or her passengers are the patients. The clinician's job, much like that of the captain, is to quickly and safely guide patients to their ultimate destination: successful completion of therapy. The captain and the clinician have unique education in this area. The captain is trained in navigation and the inner workings of his or her ship. The clinician is trained in treatment modalities and the functions of thoughts, emotions, and behaviors. Both the clinician and the captain are essential. However, in spite of their training, both the clinician and the captain of the winter sea voyage can be blind-sided.

In this analogy, cognitive biases are icebergs. They operate outside of a clinician's conscious awareness, like an iceberg just under the water's surface. In spite of extensive training and experience, cognitive biases can disrupt decision making, in some cases leading to disastrous consequences. For example, in the case of clinician predictions about suicide or violence risk, the influence of cognitive biases could quite literally be the difference between life and death. In less severe instances, cognitive biases could influence incorrect diagnoses and treatment decisions, leading to delays in or failure to achieve progress in the client's journey through therapy.

Lilienfeld and Lynn (2014) review biases in clinical decision making, including confirmation bias, overconfidence, and the bias blind spot. Confirmation bias is actively searching for information that confirms an 
initial hypothesis while also discounting evidence that is not consistent with the initial hypothesis. It can cause clinicians to avoid or distort disconfirming evidence. Overconfidence is a form of bias in which clinicians overestimate the accuracy of their judgments. Contrary to this belief, clinician confidence does not appear to be meaningfully related to judgment accuracy (Miller, Spengler, \& Spengler, 2015). Finally, the bias blind spot is a meta-bias, in which clinicians can identify bias in others' decision making but not in their own.

Turning back to our analogy and discussion of evidence-based assessment, just as the captain uses tools, such as radar, to avoid icebergs during winter travel, Youngstrom and colleagues' (2017) model highlights how objective psychological testing can serve a similar function for reducing the influence of cognitive biases on clinician decision making. Research on clinical versus statistical prediction, most recently summarized by Grove, Zald, Lebow, Snitz, and Nelson (2000), indicates that psychological testing yields more accurate decisions than clinical judgment alone (Grove et al., 2000). We believe these findings, in part, reflect that objective test data are not inherently subject to cognitive biases. This is not to say that clinicians and clinical judgment are not essential. Rather, this literature indicates that psychological testing can offer substantial added value when integrated into models of clinical decision making, as Youngstrom and colleagues have proposed.

A noteworthy strength of such a model is inclusion of a broad array of psychological testing before first contact with the patient, which could reduce the influence of confirmation bias. In this way, initial hypotheses flow from objective test data rather than clinical judgment. If the testing is broad in scope, several initial hypotheses are possible. Contrast this with the traditional approach, where testing is administered later in the assessment process. At this point, the clinician has already formed hypotheses using clinical judgment and, when faced with disconfirming evidence from testing, may be more likely to discount or distort the objective test data that call into question the initial hypotheses. When starting with psychological testing, the clinician anchors hypotheses to objective data but then also has the freedom to explore more specific areas of inquiry in the interview to arrive at a final diagnosis and an idiographic case conceptualization.

Another strength of the evidence-based model is that psychological testing can be integrated into all phases of treatment, rather than just the intake process. Youngstrom and colleagues (2017) describe, for example, how psychotherapeutic outcome measures can be used to track client progress. These are relatively short assessments designed to be administered throughout therapy, as often as every session. Past research indicates that patients of clinicians who use outcome measures have more success in therapy (see Tarescavage \& BenPorath, 2014, for a review). Here, too, we believe the utility of outcome measures is, in part, due to their immunity from cognitive biases, particularly confirmation bias. For example, a climcian could assume the client's symptoms are decreasing outside of the session without actively inquiring about them. Routine use of outcome measures puts a check on this form of bias, enabling the clinician to make changes to the treatment plan that will better reduce the client's symptoms when therapy progress has slowed.

In summary, use of psychological testing before first contact with the patient and its use throughout treatment are two of the many ways that evidence-based assessment can improve client care by reducing the influence of cognitive biases. We look forward to further development and implementation of the model. In the meantime, clinicians may be well served to follow the principles that appear to have guided the tenets of evidence-based assessment-namely, that like radar for the sea captain, psychological testing is a valuable tool that should be integrated into all phases of treatment accordingly.

\section{REFERENCES}

Grove, W. M., Zald, D. H., Lebow, B. S., Snitz, B. E., \& Nelson, C. (2000). Clinical versus mechanical prediction: A meta-analysis. Psychological Assessment, 12, 19-30. https://doi.org/10.1037/1040-3590.12.1.19

Lilienfeld, S. O., \& Lynn, S. J. (2014). Errors/biases in clinical decision making. In $R$. I. Cautin \& S. O. Lilienfeld (Eds.), The encyclopedia of clinical psychology (pp. 1-9). Hoboken, NJ: John Wiley \& Sons.

Miller, D. J., Spengler, E. S., \& Spengler, P. M. (2015). A meta-analysis of confidence and judgment accuracy in 
clinical decision making. Joumal of Counseling Psychology, 62, 553-567. https://doi.org/10.1037/cou0000105

Tarescavage, A. M., \& Ben-Porath, Y. S. (2014). Psychotherapeutic outcomes measures: A critical review for practitioners. Joumal of Clinical Psychology, 70, 808830. https://doi.org/10.1002/jclp.22080

Youngstrom, E. A., Van Meter, A., Frazier, T. W., Hunsley, J., Prinstein, M. J., Ong, M.-L., \& Youngstrom, J. K.
(2017). Evidence-based assessment as an integrative model for applying psychological science to guide the voyage of treatment. Clinical Psychology: Science and Practice. Advance online publication. https://doi.org/10.1111/cpsp.12207.

Received September 12, 2017; accepted September 12, 2017. 